\title{
Real-time sonoelastography: principles and clinical applications in tendon disorders. A systematic review
}

\author{
Federico Fusini ${ }^{1}$ \\ Francesco Langella ${ }^{2}$ \\ Alberto Busilacchi ${ }^{3}$ \\ Cosimo Tudisco 4 \\ Antonio Gigante ${ }^{3}$ \\ Alessandro Massé ${ }^{1}$ \\ Salvatore Bisicchia ${ }^{5}$
}

1 University of Turin, School of Orthopaedic and Traumatology, Turin, Italy

2 Clinical Orthopedics, University of Campania "Luigi Vanvitelli", Naples, Italy

${ }^{3}$ Clinical Orthopedics, Department of Molecular Pathology and Innovative Therapies, School of Medicine, Università Politecnica delle Marche, Ancona, Italy

${ }^{4}$ Department of Orthopaedic Surgery, University of Rome Tor Vergata, Rome, Italy

5 Orthopaedics and Traumatology, San Pietro Fatebenefratelli Hospital, Rome, Italy

Corresponding Author:

Federico Fusini

Department of Orthopaedic and Traumatology, University of Turin

Via Zuretti 29

10126 Turin, Italy

E-mail: fusinif@hotmail.com

\section{Summary}

Background: Sonoelastography (SE) is a new ultrasound-based method adopted in an increased number of scientific reports to analyse normal and pathological tendons. The aim of this study is to provide a systematic overview of clinical applications of SE in normal and pathological tendons.

Methods: A systematic research of PubMed, Ovid, and Cochrane Library electronic databases was performed according to PRISMA guideline. Two Authors searched and evaluated the articles independently; a third Author was involved to solve any disagreement. The Oxford Level of Evidence (LoE) was used to assess each article.

Results. There is an increasing interest in the application of SE in the evaluation of healthy and diseased tendons. Many different tendons are amenable for SE evaluation, such as the Achilles and patellar tendons, rotator cuff, common extensor tendons, quadriceps tendon, and the plantar fascia.

Conclusion. SE appears to be a very useful diagnostic tool, in particular in tendon pathology. This is a dynamic examination, provides an immediate evaluation of the tissue elasticity, and may be useful in recognizing tendon abnormalities and in implementing the information available with conventional US. Level of evidence: IV.

KEY WORDS: elastography, elastosonography, epicondylitis, plantarfasciitis, tendinopathy, tendon healing.

\section{Introduction}

Acute and chronic tendon disorders are nowadays an increasing issue, as the sport-active population is rising and the average life expectancy is progressively longer. The biology of tendons has been extensively studied over the past thirty years ${ }^{1}$, but information about the mechanical properties of tendons in vivo is still lacking, because the majority of the studies are conducted on animals or cadavers ${ }^{2-4}$. Palpation is the easiest tool to evaluate tissue quality, and it is still crucial in daily clinical practice. Despite that, tissue consistency, assessed by palpation, is subjective and related to the moment of the clinical examination.

Conventional ultrasonography (US), or B-Mode US, converts the radiofrequency (RF) signal in a bi-dimension image, providing morphologic and structural data of the examined tissue, but cannot give complete information about its anatomo-pathological and biomechanical properties.

Sonoelastography (SE) is a modified US; it is based on the principle that US signal coming from a structure in response to an external compression (mechanical or acoustic wave) is an indirect measurement of its biomechanical properties. Furthermore, each elastographic method differs from the others: shear wave uses shear velocity or shear modulus, which can be calculated from the velocity of the propagating wave; while quasi-static method uses strain or strain index (defined as the ratio between displacement of a target tissue and a reference tissue under probe compression). Data can be displayed in realtime on a screen (RTSE), promptly giving that information not available with other diagnostic tools. In the last twenty years, SE has gradually become popular, resulting helpful in the diagnosis and follow-up of several diseases, such as liver fibrosis, and lymph- 
nodes, and thyroid and breast neoplasms ${ }^{5}$. SE has also been applied in the musculoskeletal system to evaluate muscle elasticity, shoulder bursitis in polymyalgia rheumatica, and more recently, lateral epicondylitis, Achilles tendon, spondyloarthritis in patients with psoriasic arthritis, and rotator cuff disease ${ }^{6}$ ).

Despite the growing knowledge in this field, there is still a lack of consensus in the application of SE to detect tendon pathology. The aim of the current study is to provide a systematic review of the principles and clinical applications of RTSE in normal and pathological tendons.

\section{Materials and methods}

A literature search was conducted according to the Preferred Reporting Items for Systematic reviews and MetaAnalyses (PRISMA) guideline ${ }^{7}$. Objective of our research was to ascertain the current applications of $\mathrm{SE}$ in normal and pathological tendons.

\section{Source of studies and search strategy}

During $1^{\text {st }}$ September 2017 we performed a systematic research of PubMed, Ovid and Cochrane Library electronic databases of articles assessing the association between real time SE and tendon disorders in human subjects. Search terms were tendinopathy, tendinitis, tendon, Achilles tendon, patellar tendon, rotator cuff, plantar fascia, plantar fascitis, epicondyle, epicondylitis, real time sonoelastography, elastography, real time elastography and sonoelstography. Mesh terms strategy was the following: (tendinopathy; OR tendinitis; OR tendon; OR achilles tendon; OR patellar tendon; OR rotator cuff; OR plantar fascia; OR epicondyle; OR epicondylitis) AND (real time sonoelastography; OR real time elastography; OR sonoelastography; OR elastography).

\section{Study selection and eligibility criteria}

Two Authors (FF and FL) performed the search and evaluated the articles independently. A third Author (SB) was involved to solve any disagreement. Each researcher reviewed the title and abstract of all the articles. Furthermore, the reference list of each article was screened in order to find any additional original articles.

We excluded from our research all repeated articles, case reports, editorials, technical notes and review articles. Articles not in English, and basic science, preclinical and cadaver studies were also excluded.

Reviewers used the Oxford Level of Evidence ${ }^{8}$ (LoE) to assess each clinical article. The Oxford Level of Evidence is an easy and effective tool to evaluate the strength of results in research studies. This classification rapidly estimates the methodological quality of each article. According to this system, articles were classified from level 1 to 5 , where higher LoE means better methodological quality and lower risk of bias.

This article was conducted according to the ethical standards of the Journal ${ }^{9}$.

\section{Results}

Three hundred and eleven articles were identified through databases search. After duplication removal and study screening, 236 articles were selected. According to the inclusion and exclusion criteria, 60 fulltext articles ${ }^{10-70}$ were included (Fig. 1). Results were reported into different sections, according to anatomical regions.

\section{Normal Achilles tendon}

The Achilles tendon is the most studied musculoskeletal region with SE. Authors initially focused on the description of SE patterns in normal tendons, and then moved to pathological conditions.

At the beginning, a chromatic scale was proposed to analyse healthy tendon properties (Fig. 2).

De Zordo et al. divided tissues into 3 grades: grade 1, blue (hardest tissue) to green (hard tissue); grade 2, yellow (intermediate tissue); or grade 3 , red (soft tissue). A stiff pattern was observed in $86.7 \%$ of patients, while an area of mild softening was present in $12.1 \%$ of cases. In particular, a mild softening on SE analysis was present in areas of normal US appearance ${ }^{10}$. Similarly, Dragonaki et al. ${ }^{11}$ identified two different SE patterns in normal Achilles tendons. Type 1 (homogenously green/blue) pattern was observed in $38 \%$ of tendons, while type 2 (green with longitudinal red stripes) patter was reported in $62 \%$ of cases. Yamamoto et al. ${ }^{12}$ observed 3 patterns: green/blue for grade 1; yellow for grade 2 and red for grade 3 . While asymptomatic tendons showed a normal appearance on US in $97 \%$ of cases, only $63 \%$ of those had a type 1 pattern, the remaining were type 2.

Subsequently, Arda et al. ${ }^{13}$ reported on elasticity values of Achilles tendons using a numeric scale in healthy volunteers, with a mean of $51.5 \pm 25.1 \mathrm{kPa}$ as Young modulus.

During aging, Achilles tendon exhibited an increased stiffness when compared to young adults ${ }^{14,15}$; however, other Authors did not find any correlation ${ }^{16}$. A positive correlation was found between tendon stiffness and $\mathrm{BMI}^{17}$; results in smokers are controversial ${ }^{17,18}$.

SE was also adopted in detecting early modifications of Achilles tendons in athletes. In volleyball players, Achilles tendon showed increasing thickness and reduced stiffness in comparison with healthy volunteers with same age and body mass index (BMI), indicating a potential early tendon degeneration ${ }^{19}$. At the beginning of the season tendon abnormalities were observed in $54,2 \%$ of football players, despite all were asymptomatic. At the end of the season, $27.3 \%$ of them became symptomatic and all of them had SE abnormalities. Interestingly, asymptomatic patients with normal imaging at the beginning of the season did not develop tendinopathies or tendon ruptures ${ }^{21}$.

Marathon runners had an increased tendon thickness, and intratendinous softening before the race compared with healthy volunteers. After the race, tendons showed reduction of tendon stiffness and increased Doppler signal. After 6 weeks, those changes spontaneously solved; however, $19 \%$ of runners developed 


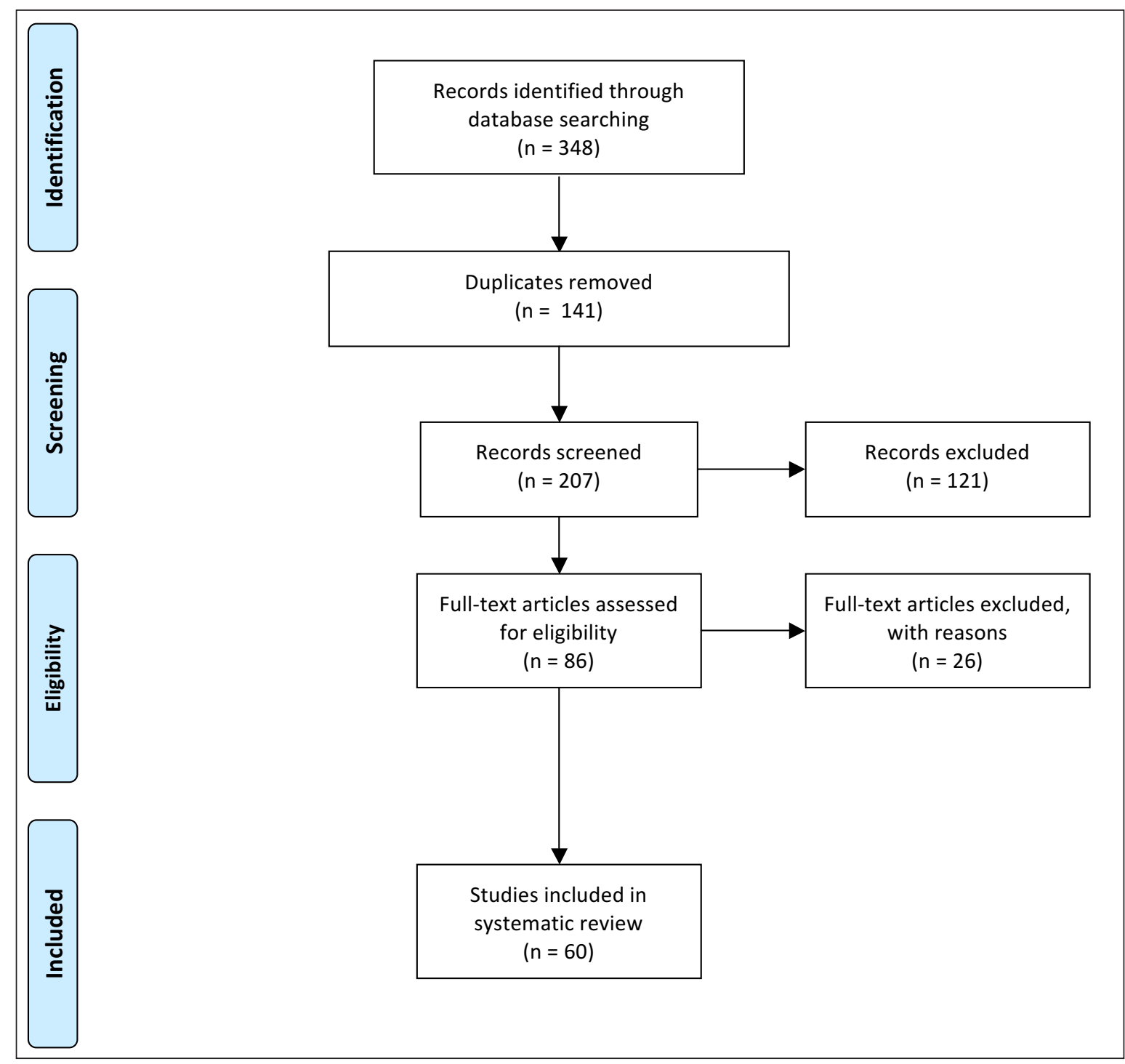

Figure 1. PRISMA (Preferred Reporting Items for Systematic review and Meta-Analysis) flow diagram of studies screened, selected and included in systematic review.

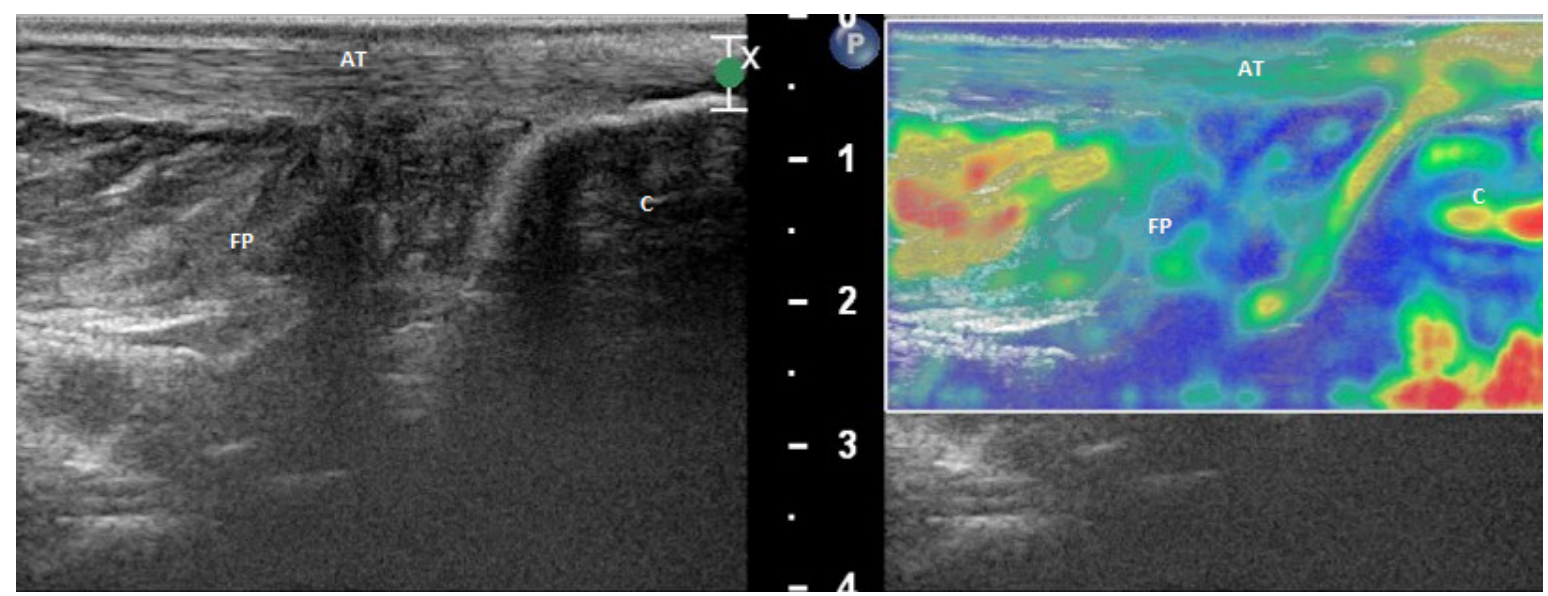

Figure 2. US examination (left side) and RTSE (right side) of normal Achilles tendon of a healthy volunteer. Healthy Achilles tendon showed a prevalence of blue/green pattern. AT, Achilles tendon; C, calcaneous; FP, Kager's fat pat. 
tendon symptoms. Again, symptomatic patients already presented SE alterations at baseline, significantly related with pain 20 .

After long term exercise, Achilles tendon stiffness was higher than that of infrequent exercisers on nondominant leg but not on dominant ankle 22 . Same results were confirmed after eccentric heel drop exercises $^{23}$.

The correlation between US and RTSE analysis in healthy Achilles tendons has been reported perfect $(\mathrm{K}=1)^{10,17}$. Furthermore, the intra observer repeatability was reported as almost perfect, while inter observer repeatability was found to be moderate ${ }^{12}$ to excellent ${ }^{17}$. However these results were denied by Payne et al., who reported poor reproducibility during same day and consecutive day measures especially with the changes of foot position ${ }^{24}$.

\section{Achilles tendinopathy}

Achilles tendinopathy is a common cause of morbidity and performance deficit among general population and athletes ${ }^{25}$. Early diagnosis allows to improve outcomes and to guide treatment. Patients suffering from Achilles tendinopathy showed the reduction of axial and compressive strain SE patterns, that seem to indicate an alteration of mechanical properties specific to the anatomical region affected by tendinopathy ${ }^{26}$.

In adjunct of qualitative analysis, Dirrichs et al. ${ }^{27}$ proposed quantitative analysis of Young's modulus. Symptomatic patients had significantly lower values $(53.4+/-23.2 \mathrm{kPa})$ than healthy subjects (154.2 +/$28.3 \mathrm{kPa}$ ) with close correlation with clinical outcomes $(r=0.81)$. Healthy tendons showed a prevalence of hard (red) and intermediate (yellow) values, while most of affected tendons had soft (blue) or intermediate values.

De Zordo et al. graded normal and tendinopathic Achilles tendons into 3 grades: grade 1: blue green pattern (hardest to intermediate tissue), grade 2: yellow (soft tissue), and grade 3: red (softest tissue). A hard pattern was seen in $93 \%$ of patients, with focused areas of grade 3 in $57 \%$ of patients, and the middle portion was the most interested. On the other hand, healthy volunteers reported SE grade 1 in $93 \%$ of the cases and no grade $3^{28}$.

In those patients with symptomatic Achilles tendons but normal US appearance, SE was able to highlight very early changes in tissue elasticity, due to initial oedema and inflammation, usually missed at conventional US $27-31$.

SE demonstrated high to excellent sensitivity, specificity and accuracy, and also a high agreement with US ( $\mathrm{k}=0.81)$ and clinical examination $(\mathrm{k}=0.91)^{28,32}$. Moreover, in patients with history of tendinopathy, but normal US appearance, SE recorded an higher number of tendon abnormalities than conventional US as areas of softening ${ }^{31}$.

Sconfienza et al. ${ }^{33}$ reported symptomatic tendons to be thicker, fragmented, and harder at tendon body portion. Both fragmentation and loss of fibrillar texture showed an inverse correlation with tendon thickness. Zhang et al. ${ }^{34}$ reported similar results in chronic inser- tional tendinopathy, especially in patients with calcifications.

Gatz et al. found SE to be more sensitive than conventional US and PD in the monitoring of tendon healing under therapy and positively correlated with symptoms improvement ${ }^{35}$.

\section{Achilles tendon ruptures}

Tan et al. ${ }^{36}$ compared tissue stiffness of surgically repaired Achilles tendons in amateur football players and healthy amateur footballers. Surgical repaired tendons showed heterogeneous structure with hardest pattern in $64.9 \%$ of cases and hard pattern in the rests, while healthy tendons had homogeneous structure and hardest pattern in $15 \%$, hard in $64.2 \%$, and intermediate in the remaining.

Healthy Achilles tendons have a higher Young modulus $(291.91 \pm 4.38)$ compared with ruptured tendons $(56.48 \pm 68.59 \mathrm{kPa})^{37}$.

Busilacchi et al. reported that percutaneously repaired tendons became stiffer over time, especially at myotendinous junction and at the site of the sutured lesion, resulting in a significantly higher stiffness than both the contralateral tendon and healthy volunteers. Peak of thickness occurred at 6 months, with a tendency to reduce at 1 year, but never achieving a normal value; while functional score gradually improved with return to previous sport activity ${ }^{38}$. Similar results were reported also after open repairs ${ }^{39}$.

\section{Other pathologic conditions of the Achilles tendon}

In patient with unilateral clubfoot, the affected tendons were stiffer than healthy controls ${ }^{40}$. On the opposite side, diabetic patients with foot ulcers had thicker but softer tendons than healthy controls and diabetic patients without foot ulcers ${ }^{41}$.

In patients affected by ankylosing spondylitis, tendon pain was higher in patients with areas of softening. In particular, the distal third was the most commonly affected site and it was commonly associated with both bone erosion and enthesis enlargement ${ }^{15,42}$.

Onal et al. reported that patients with acromegaly had thicker tendon than healthy subjects, especially in active phase of disease. SE analysis showed an equal distribution of hard and soft patterns, however the analysis revealed a prevalence of intermediate pattern ${ }^{43}$.

In patients with cerebral palsy, Achilles tendon resulted to be shorter and stiffer than healthy subjects, and a positive correlation was found between strain ratio, age, tendon length, and thickness ${ }^{44}$.

\section{Patellar ad quadriceps tendons}

Despite patellar tendon pathology is very common among athletes and amateur players, SE is still not widely used, and normal and pathological appearance is not well established.

Porta et al. ${ }^{45}$ defined the normal appearance of patellar tendon at SE as a predominance of green pattern at proximal, middle, and distal portions. However the colour scale of sonographer ranged from red to green (red is defined as hard and green as soft tissue), and 
these results are in contrast with other Authors that found normal tendon to be harder and tendinopathic tendons to be softer $27,31,32$. Furthermore, smoking habit made patellar tendon thinner and harder ${ }^{18}$.

At the evaluation of the elasticity ratio, values $($ mean $\pm \mathrm{SD}$ ) of $1.47 \pm 0.64$ for proximal, $4.38 \pm 1.36$ for middle, and $3.32 \pm 1.20$ for distal portions were reported. Intra and inter observer analysis showed high agreement. The Young modulus of healthy patients was higher $(176.8+/-18.2 \mathrm{kPa})$ than tendinopathic ones $(56.3+/-18.3 \mathrm{kPa})^{27}$.

Ozcan et al. reported same SE pattern in healthy volunteers and healthy professional athletes; proximal portion of patellar tendon resulted to be was stiffer than distal part ${ }^{46}$. Patellar tendon stiffness was found to be higher in male than female as well as in patients with lower BMI than obese individuals ${ }^{47}$. An excellent intraobserver and interday reliability and a good interobserver reliability was reported in healthy volunteers ${ }^{48}$.

In volleyball players, patients with tendinopathy have softer tendons ${ }^{28}$, while asymptomatic players had harder tendons. Moreover, symptomatic tendons were also thicker and had lower clinical score ${ }^{49}$ that closely correlated with SE values ${ }^{27}$. The combination of US and SE achieved higher sensitivity and accuracy, but a lower specificity than the combination of Doppler and US ${ }^{49}$. However, when SE was coupled with US and Doppler, the diagnostic accuracy reached $100 \% 27$.

In symptomatic patients, sometimes, conventional US evaluation could show normal pattern, especially in the very first phases. In those cases, SE analysis could show some alterations as areas of softening, in more than $70 \%$ of cases $^{31}$. In these cases, SE appeared to be a more sensitive tool to describe symptoms than Doppler and US 35 .

After knee surgery (i.e. tibial osteotomy), patellar tendon showed biomechanical alterations, such as tissue contracture, increasing stiffness, and thickness than healthy tendons ${ }^{50}$. On the other hand, also when patellar tendon is directly involved [i.e. anterior cruciate ligament reconstruction with auto-graft bonepatellar-bone (BTB) technique], the tendon showed some alterations: decrease in strain index, along with thickening and shortening of the tendon compared with healthy contralateral sides ${ }^{51}$.

Only few studies were found dealing with quadriceps tendon. Healthy volunteers had prevalence of hard characteristics ${ }^{46}$. Teber et al. ${ }^{52}$ reported that normal quadriceps tendon patterns tended to change in case of chronic renal failure, in particular a substantial intratendinous softening occurred.

\section{Shoulder}

Arda et al. ${ }^{13}$ reported the Young modulus of healthy supraspinatus tendons to be $31.2 \pm 13 \mathrm{kPa}$, with higher values in males, and without any correlation with age. On the other hand, Baumer et al. found an increase of tendon stiffness with age ${ }^{53}$.

In collegiate swimmers, years of participation to com- petition were significantly related with tendon thickness, while tendon appeared softer year after year ${ }^{54}$. According to the Authors, this may be connected with the high prevalence of shoulder impingement and tendinopathy in swimmer athletes.

Rotator cuff diseased tendons had soft appearance 28 that directly correlated with tendon degeneration at $\mathrm{MRI}^{55}$. Recently, a significant correlation were found between T2 value of MRI and SE, suggesting an improvement of quantitative evaluation of rotator cuff 56 . SE was able to find alterations in more than $80 \%$ of cases in symptomatic patients with normal US. In $88.4 \%$ of positive findings, rotator cuff tendons appeared stiff, and inflammation/oedema of the subacromial bursa and surrounding tissues were associated. Elastographic signs of biceps tendinopathy were reported only in $11.5 \%$ of patients ${ }^{31}$.

In case of shoulder impingement, supraspinatus tendons had higher strain index than healthy contralateral side ${ }^{57}$.

Seo et al. reported on the appearance of biceps tendons at SE: normal tendon appeared blue/green, while tendinopathic soft tendons appeared yellow/red. Furthermore, a positive correlation with US was found. Inter-observer reliability of SE was almost perfect; while accuracy, sensibility and specificity were high ${ }^{58}$.

Tendon quality is one of the most important prognostic factors for surgeon performing rotator cuff repair. In case of small supraspinatus tears, several Authors $53,59,60$ reported the torn tendons to be softer (mean strain index $0.75 \pm 0.08$ ) compared with the contralateral healthy shoulder $(1.01 \pm 0.07)$ (Figs. 3$5)$. A negative correlation between strain index and pain, and a strong positive correlation with functional scores ${ }^{59}$ was also reported.

SE showed a good to very good intra and inter user and day by day repeatability ${ }^{61}$ that could be very useful in the preoperative assessment of tendon quality 60 .

\section{Common extensor origin}

Healthy common extensor tendons had a hard structure in $94 \%$ of cases and mild softening only in $4 \% 62$. Healthy patients had higher values of Young modulus $(176.2+/-18.2 \mathrm{kPa})$ than patients affected by lateral epicondylitis $(64.1+/-29.3 \mathrm{kPa})$ and these findings positively correlated with functional scores ${ }^{27}$. In patients with symptomatic lateral epicondylitis, SE showed a hard pattern in $33 \%$ of tendons, and different grades of softening in $67 \%$. Those patients had a significantly lower strain index in their common extensor tendon origins ${ }^{63}$, indicating that the symptomatic tendons were softer than asymptomatic ones ${ }^{64}$ or had intermediate values ${ }^{27}$.

Authors reported good correlation between SE and US and also a positive correlation with functional scores $^{27}$. Furthermore, a better capability of SE in detecting early changes compared with US and Doppler was observed 35,65 . The sensitivity of SE was $100 \%$, the specificity $89 \%$, and the accuracy $94 \%$, with clinical examination as the reference standard ${ }^{62}$. Howev- 


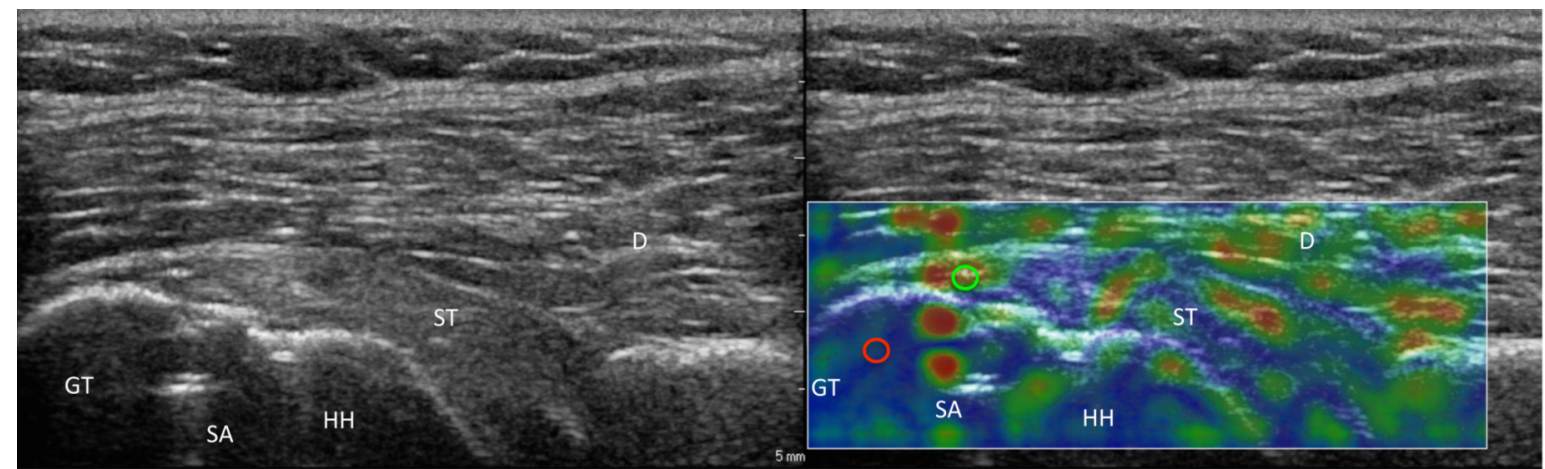

Figure 3. US examination (left side) and RTSE (right side) of the right shoulder of a 65-year-old woman, right hand dominant, 2 years after arthroscopic rotator cuff repair. The red circle is located in the bone, while the green circle represents tendon degeneration. SA, suture anchor; D, deltoid; GT, greater tuberosity; $\mathrm{HH}$, humeral head.

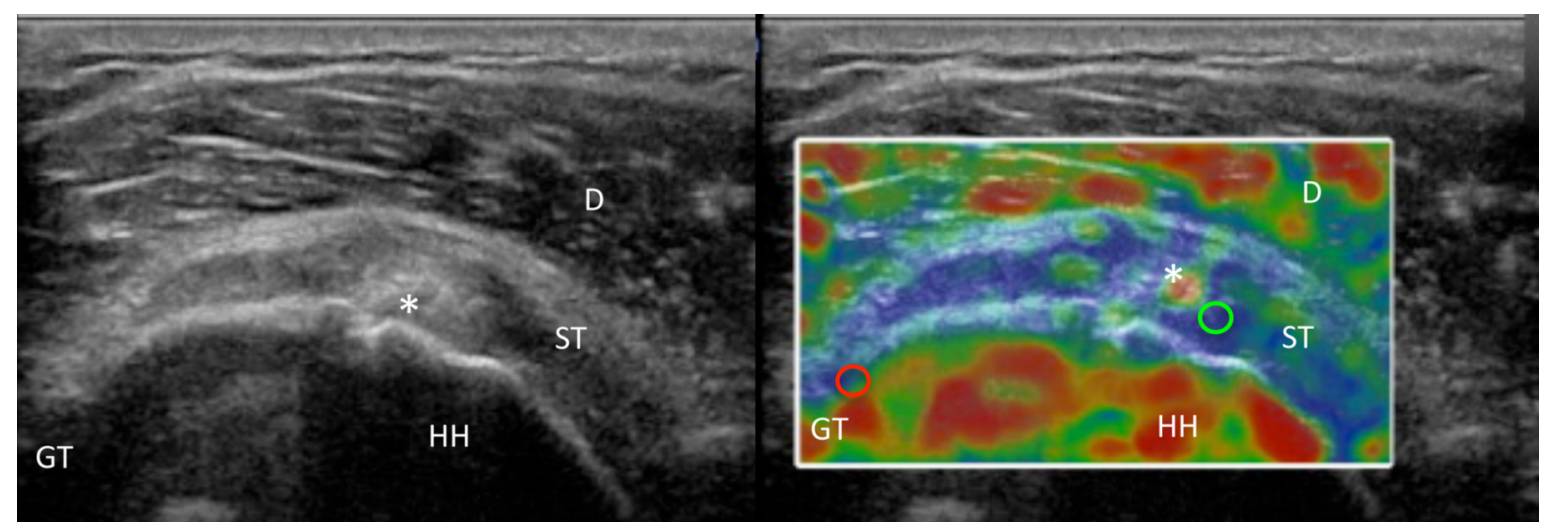

Figure 4. US examination (left side) and RTSE (right side) of the right shoulder of a 64-year-old man, right hand dominant, with a rotator cuff tear. US showed a $2 \mathrm{~cm}$ supraspinatus tendon tear (asterisks). The red circle is located in the bone, while the green circle is located in the torn tendon. D, deltoid; GT, greater tuberosity; $\mathrm{HH}$, humeral head.

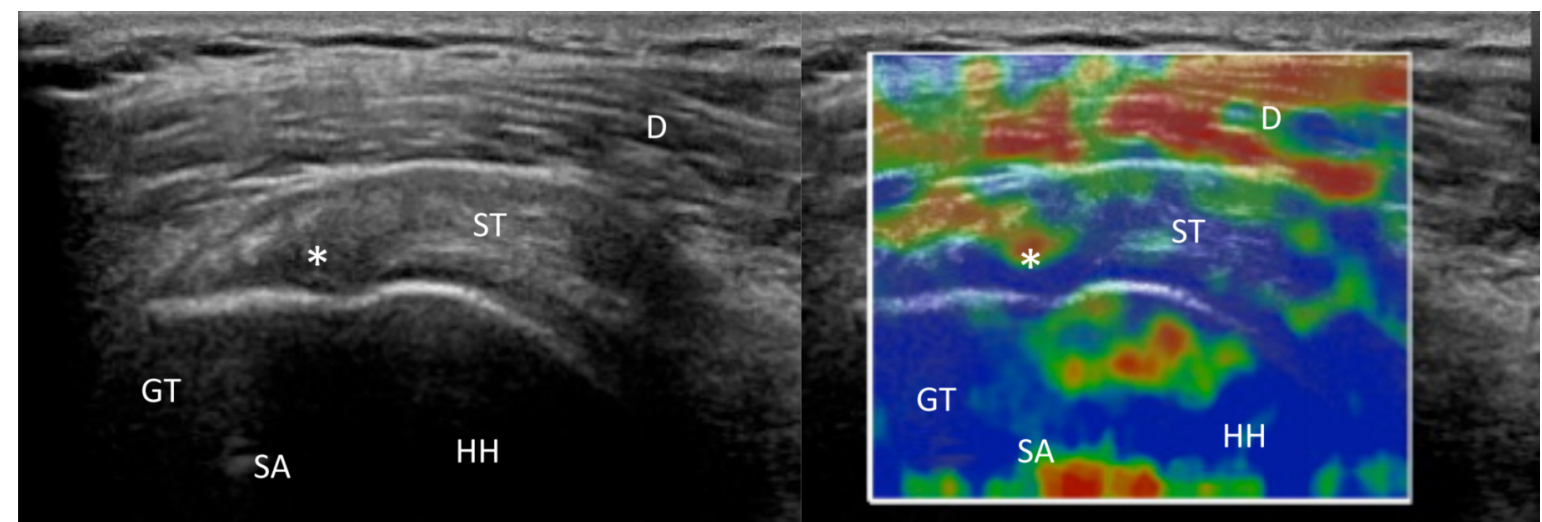

Figure 5. US examination (left side) and RTSE (right side) of the right shoulder of a 58-year-old man, right hand dominant, operated on the right shoulder, who developed a re-tear/non-healing (asterisks) after surgery. The red circle represents is located in the bone, while the green circle is located in the torn tendon. SA, suture anchor; D, deltoid; GT, greater tuberosity; $\mathrm{HH}$, humeral head.

er, another study reported that the combination of SE, US, and Doppler reached only $84 \%$ accuracy 27 .

In patients with symptomatic lateral epicondylitis and negative US findings, Galletti et al. ${ }^{31}$ reported areas of softening at SE, representing signs of peritendinopathy and enthesitis. 


\section{Plantar fascia}

Healthy plantar fascia is homogeneously hard ${ }^{66}$, while it is soft in plantar fasciitis. Moreover, a correlation between age, pain, and SE was found, with a high interobserver reproducibility and higher accuracy for SE than US66

Softening of plantar fascia with ageing and fasciitis were also confirmed by $\mathrm{Wu}$ et al. ${ }^{67,68}$. The Authors speculated that the loss of elasticity seemed directly related with plantar fasciitis not detectable with conventional US. On the other hand, the increased BMI induced lower fascia stiffness and high thickness ${ }^{69}$.

In symptomatic patients with normal US, SE was able to detect positive findings for plantar fasciitis in $72.2 \%$ of cases. In contrast with previous studies, the fascia was found homogeneously hard, probably because of anelastic tissue alteration. Tissue oedema and inflammation, were present in the surrounding tissues. However, in $27.7 \%$ of cases the results of SE were negative or inconclusive, despite the symptoms of the patients ${ }^{31}$

SE can be used to monitor treatment success. In patients with plantar fasciitis, the treatment with collagen injection induced SE changes with hardening of plantar fascia 70

\section{Level of evidence}

The systematic research of the literature did not provide any high LoE (I or II) experimental work. In most cases, articles reached LoE III as best result. Our research reported $66.67 \%(37 / 60)$ LoE III and $33.33 \%(23 / 60)$ LoE IV papers. LoE V were excluded from the research as an exclusion criterion. A resume of articles' major findings and LoE can be found in Table I.

\section{Discussion}

Nowadays, SE is still in a pioneering era in musculoskeletal tissues, however it appears to be a very useful tool for the diagnostic process in several soft tissues, with particular focus on tendons. The literature might be considered still poor, although the number of publications is rapidly increasing.

Most of the articles included in this systematic review reveal a low LoE. Even if the results are promising, the absolute lack of randomized controlled trials (RCTs) does not allow making any definitive recommendations about the use of SE as gold standard diagnostic tool for tendon pathology.

In addition, there are several types of SE such as shear wave, transient, or strain elastography. Despite these different methods, and the wide kind of results, all studies reported concordant and homogeneous results, with little variability $13,17,29,32$. The little differences between results are probably based on nonhomogeneous populations investigated. None of these studies is taking in the account differences between chronic or acute tendinopathy.

Several limitations should be acknowledged. The lack of RCTs exposes our analysis to some bias, such as low methodological quality, low number of patients, retrospective design, or lack of blinding. Moreover, SE is operator-dependent (like US) requiring a long learning curve. However, the diagnostic procedure demonstrated high performance of reproducibility 45 . This technology is nowadays in the hands of few specialized radiologists, who are trying to give a deeper interpretation to the data coming out from new studies. But, we foresee also a potential role in the daily practice of the orthopaedic surgeon and sports medicine specialist, either in the clinic (as diagnostic and follow-up tool), or in the operative room to assess the proper tension and elasticity of a tissue during surgery (i.e. Achilles tendon repair). In fact, we know very little about the in vivo implications of a proper tensioning applied by the surgeon on a tendon in the healing process. In this view, new clinical studies could reveal the content of one of the "black boxes" of musculoskeletal pathology.

Several studies demonstrated SE is able to identify tendinous alterations in patients with clinical symptoms and negative US and colour Doppler. Despite these results, the role of SE as a predictive screening test for tendon rupture is still debated and the evidence is not sufficient. We are confident that future developments will be able to increase our ability in identifying tendon abnormalities and in predicting tendon ruptures, especially in athletes ${ }^{27,49,58}$.

Similarly, many Authors agree that SE is a valuable tool in recognizing tendon abnormalities and in implementing the information available with US 17,28,31,49,62. Surprisingly two recent cadaveric studies reported for the first time a total agreement between SE and histological findings, while US had a lower accuracy ${ }^{71,72}$. SE was also able to detect tissue changes in symptomatic patients with normal $\mathrm{US}^{31}$, and to screen athletes at risk of developing symptoms during the season $^{21}$.

For these reasons, SE is considered a valuable tool to valuate "in vivo" and in a non-invasive way the biomechanical properties of various tendons ${ }^{16}$ bypassing artefacts of surgical repair, such as tendons sutures ${ }^{38}$

\section{Conclusion}

SE appears to be a very useful diagnostic tool, in particular on tendons. This is a dynamic examination, provides an immediate evaluation of the tissue elasticity, and may be useful in recognizing tendon abnormalities and in implementing the information available with conventional US.

\section{References}

1. Andarawis-Puri N, Flatow EL, Soslowsky LJ. Tendon Basic Science: Development, Repair, Regeneration, and Healing. Journal of orthopaedic research: official publication of the Orthopaedic Research Society. 2015;33(6):780-784. 

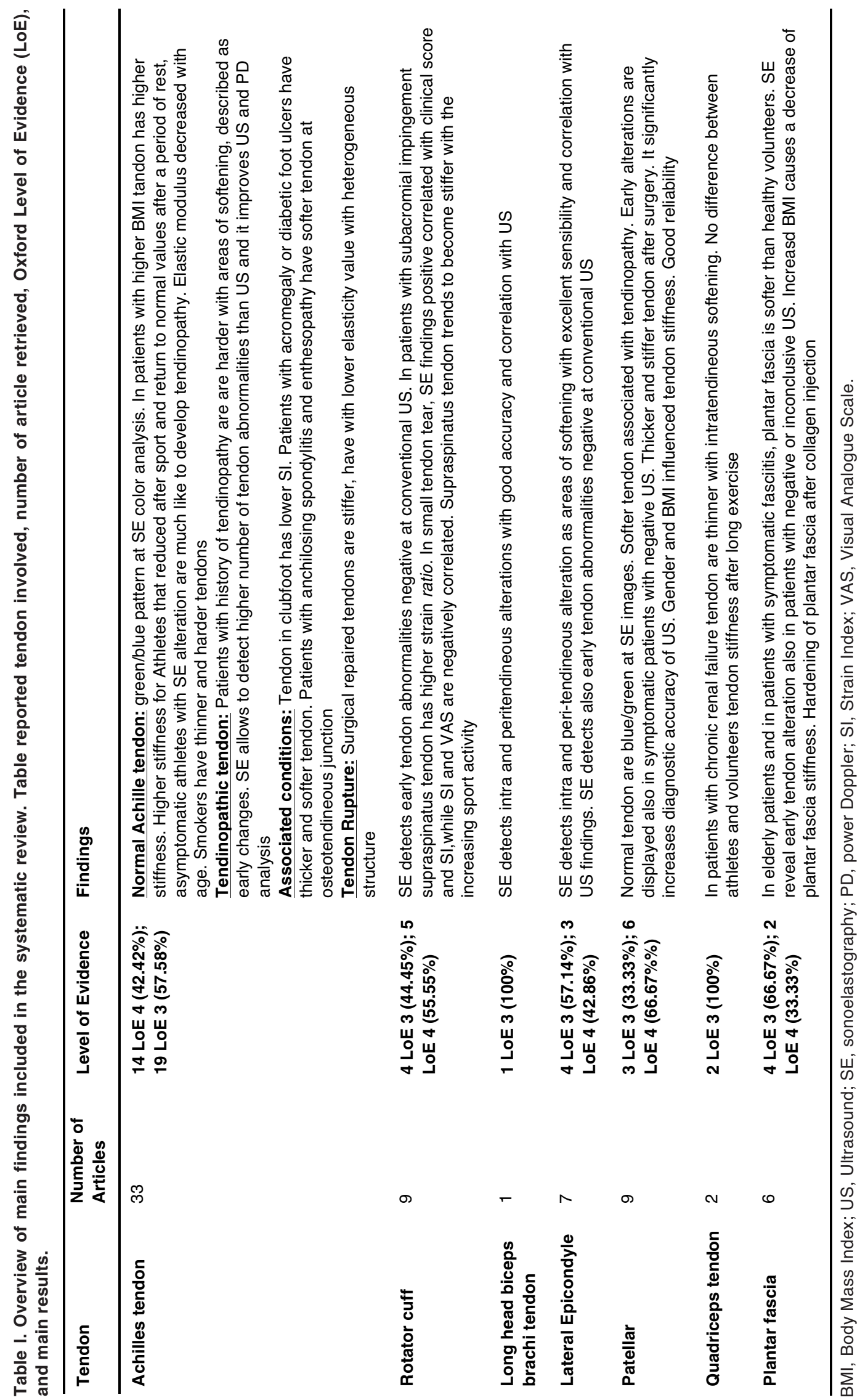
2. Woo SL. Mechanical properties of tendons and ligaments. I. Quasi-static and nonlinear viscoelastic properties. Biorheology. 1982;19(3):385-396

3. Woo SL, Fisher MB, Feola AJ. Contribution of biomechanics to management of ligament and tendon injuries. Molecular \& cellular biomechanics: MCB. 2008;5(1):49-68.

4. Woo SL, Orlando CA, Camp JF, Akeson WH. Effects of postmortem storage by freezing on ligament tensile behavior. Journal of biomechanics. 1986;19(5):399-404.

5. Giuseppetti GM, Martegani A, Di Cioccio B, Baldassarre S Elastosonography in the diagnosis of the nodular breast lesions: preliminary report. La Radiologia medica. 2005;110(12):69-76.

6. Klauser AS, Miyamoto H, Bellmann-Weiler R, Feuchtner GM, Wick MC, Jaschke WR. Sonoelastography: musculoskeletal applications. Radiology. 2014;272(3):622-633.

7. Liberati A, Altman DG, Tetzlaff J, Mulrow C, Gotzsche PC, loannidis JP, et al. The PRISMA statement for reporting systematic reviews and meta-analyses of studies that evaluate health care interventions: explanation and elaboration. Journal of clinical epidemiology. 2009;62(10):e1-34

8. Group OLoEW. The Oxford 2011 levels of evidence. Oxford centre for evidence-based medicine Oxford, UK. 2011.

9. Padulo J, Oliva F, Frizziero A, Maffulli N. Muscles, Ligaments and Tendons Journal - Basic principles and recommendations in clinical and field science research: 2016 update. MLTJ. 2016;6(1):1-5.

10. De Zordo T, Fink C, Feuchtner GM, Smekal V, Reindl M, Klauser AS. Real-time sonoelastography findings in healthy Achilles tendons. AJR American journal of roentgenology. 2009;193(2):W134-138.

11. Drakonaki EE, Allen GM, Wilson DJ. Real-time ultrasound elastography of the normal Achilles tendon: reproducibility and pattern description. Clinical radiology. 2009;64(12):11961202.

12. Yamamoto $Y$, Yamaguchi S, Sasho T, Fukawa T, Akatsu $Y$, Nagashima K, et al. Quantitative Ultrasound Elastography With an Acoustic Coupler for Achilles Tendon Elasticity: Measurement Repeatability and Normative Values. Journal of ultrasound in medicine: official journal of the American Institute of Ultrasound in Medicine. 2016;35(1):159-166.

13. Arda K, Ciledag N, Aktas E, Aribas BK, Kose K. Quantitative assessment of normal soft-tissue elasticity using shear-wave ultrasound elastography. AJR American journal of roentgenology. 2011;197(3):532-536.

14. Slane LC, Martin J, DeWall R, Thelen D, Lee K. Quantitative ultrasound mapping of regional variations in shear wave speeds of the aging Achilles tendon. European radiology. 2017;27(2):474-482

15. Turan A, Teber MA, Yakut ZI, Unlu HA, Hekimoglu B. Sonoelastographic assessment of the age-related changes of the Achilles tendon. Medical ultrasonography. 2015;17(1):58-61.

16. Fu S, Cui L, He X, Sun Y. Elastic Characteristics of the Normal Achilles Tendon Assessed by Virtual Touch Imaging Quantification Shear Wave Elastography. Journal of ultrasound in medicine: official journal of the American Institute of Ultrasound in Medicine. 2016;35(9):1881-1887.

17. Capalbo E, Peli M, Stradiotti P. Sonoelastography of the distal third of the Achilles tendon in asymptomatic volunteers: correlation with anthropometric data, ultrasound findings and reproducibility of the method. La Radiologia medica. 2016;121 (8):667-674

18. Agladioglu K, Akkaya N, Gungor HR, Akkaya S, Ok N, Ozcakar L. Effects of Cigarette Smoking on Elastographic Strain Ratio Measurements of Patellar and Achilles Tendons. Journal of ultrasound in medicine: official journal of the American Institute of Ultrasound in Medicine. 2016;35(11):2431-2438

19. Balaban M, Idilman IS, Ipek A, Ikiz SS, Bektaser B, Gumus M.
Elastographic Findings of Achilles Tendons in Asymptomatic Professional Male Volleyball Players. Journal of ultrasound in medicine: official journal of the American Institute of Ultrasound in Medicine. 2016;35(12):2623-2628.

20. Ooi CC, Schneider ME, Malliaras P, Counsel P, Connell DA Prevalence of morphological and mechanical stiffness alterations of mid Achilles tendons in asymptomatic marathon runners before and after a competition. Skeletal radiology. 2015;44(8):1119-1127.

21. Ooi CC, Schneider ME, Malliaras $P$, Jones D, Saunders $S$, McMahon A, et al. Sonoelastography of the Achilles Tendon: Prevalence and Prognostic Value Among Asymptomatic Elite Australian Rules Football Players. Clinical journal of sport medicine: official journal of the Canadian Academy of Sport Medicine. 2016;26(4):299-306.

22. Siu WL, Chan CH, Lam CH, Lee CM, Ying M. Sonographic evaluation of the effect of long-term exercise on Achilles tendon stiffness using shear wave elastography. Journal of science and medicine in sport. 2016;19(11):883-887.

23. Leung WKC, Chu KL, Lai C. Sonographic evaluation of the immediate effects of eccentric heel drop exercise on Achilles tendon and gastrocnemius muscle stiffness using shear wave elastography. PeerJ. 2017;5:e3592.

24. Payne $C$, Webborn N, Watt $P$, Cercignani M. Poor reproducibility of compression elastography in the Achilles tendon: same day and consecutive day measurements. Skeletal radiology. 2017;46(7):889-895.

25. Maffulli N, Wong J, Almekinders LC. Types and epidemiology of tendinopathy. Clinics in sports medicine. 2003;22(4):675692.

26. Chimenti RL, Bucklin M, Kelly M, Ketz J, Flemister AS, Richards MS, et al. Insertional achilles tendinopathy associated with altered transverse compressive and axial tensile strain during ankle dorsiflexion. Journal of orthopaedic research: official publication of the Orthopaedic Research Society. 2017;35(4):910-915.

27. Dirrichs T, Quack V, Gatz M, Tingart M, Kuhl CK, Schrading S. Shear Wave Elastography (SWE) for the Evaluation of $\mathrm{Pa}$ tients with Tendinopathies. Academic radiology. 2016;23 (10):1204-1213.

28. De Zordo T, Chhem R, Smekal V, Feuchtner G, Reindl M, Fink $C$, et al. Real-time sonoelastography: findings in patients with symptomatic achilles tendons and comparison to healthy volunteers. Ultraschall in der Medizin. 2010;31(4):394-400.

29. Aubry S, Nueffer JP, Tanter M, Becce F, Vidal C, Michel F. Viscoelasticity in Achilles tendonopathy: quantitative assessment by using real-time shear-wave elastography. Radiology. 2015;274(3):821-829.

30. Petrescu PH, Izvernariu DA, lancu C, Dinu GO, Crisan D, Popescu SA, et al. Evaluation of normal and pathological Achilles tendon by real-time shear wave elastography. Romanian journal of morphology and embryology = Revue roumaine de morphologie et embryologie. 2016;57(2Suppl):785-790.

31. Galletti S, Oliva F, Masiero S, Frizziero A, Galletti R, Schiavone $\mathrm{C}$, et al. Sonoelastography in the diagnosis of tendinopathies: an added value. Muscles, ligaments and tendons journal. 2015;5(4):325-330.

32. Ooi CC, Schneider ME, Malliaras P, Chadwick M, Connell DA. Diagnostic performance of axial-strain sonoelastography in confirming clinically diagnosed Achilles tendinopathy: comparison with B-mode ultrasound and color Doppler imaging. Ultrasound in medicine \& biology. 2015;41(1):15-25.

33. Sconfienza LM, Silvestri E, Cimmino MA. Sonoelastography in the evaluation of painful Achilles tendon in amateur athletes. Clinical and experimental rheumatology. 2010;28(3):373-378.

34. Zhang Q, Cai Y, Hua Y. Sonoelastography shows that Achilles tendons with insertional tendinopathy are harder than asymptomatic tendons. 2016. 
35. Gatz M, Schrading S, Dirrichs T, Betsch M, Tingart M, Rath B, et al. Topical polidocanol application in combination with static stretching in tendinopathies: a prospective pilot study. Muscles, ligaments and tendons journal. 2017;7(1):88-97.

36. Tan S, Kudas S, Ozcan AS, Ipek A, Karaoglanoglu M, Arslan $\mathrm{H}$, et al. Real-time sonoelastography of the Achilles tendon: pattern description in healthy subjects and patients with surgically repaired complete ruptures. Skeletal radiology. 2012;41 (9):1067-1072.

37. Chen XM, Cui LG, He P, Shen WW, Qian YJ, Wang JR. Shear wave elastographic characterization of normal and torn achilles tendons: a pilot study. Journal of ultrasound in medicine: official journal of the American Institute of Ultrasound in Medicine. 2013;32(3):449-455.

38. Busilacchi A, Olivieri M, Ulisse S, Gesuita R, Skrami E, Lording $\mathrm{T}$, et al. Real-time sonoelastography as novel follow-up method in Achilles tendon surgery. Knee surgery, sports traumatology, arthroscopy: official journal of the ESSKA. 2016;24 (7):2124-2132.

39. Zhang LN, Wan WB, Wang YX, Jiao ZY, Zhang LH, Luo YK, et al. Evaluation of Elastic Stiffness in Healing Achilles Tendon After Surgical Repair of a Tendon Rupture Using In Vivo Ultrasound Shear Wave Elastography. Medical science monitor: international medical journal of experimental and clinical research. 2016;22:1186-1191.

40. Masala S, Manenti G, Antonicoli M, Morosetti D, Claroni G, Guglielmi G, et al. Real time evaluation of monolateral clubfoot with sonoelastography. La Radiologia medica. 2014;119(8): 601-606.

41. Evranos B, Idilman I, Ipek A, Polat SB, Cakir B, Ersoy R. Realtime sonoelastography and ultrasound evaluation of the Achilles tendon in patients with diabetes with or without foot ulcers: a cross sectional study. Journal of diabetes and its complications. 2015;29(8):1124-1129.

42. Turan A, Tufan A, Mercan R, Teber MA, Tezcan ME, Bitik B, et al. Real-time sonoelastography of Achilles tendon in patients with ankylosing spondylitis. Skeletal radiology. 2013;42(8): 1113-1118.

43. Onal ED, Ipek A, Evranos B, Idilman IS, Cakir B, Ersoy R. Structural tendon changes in patients with acromegaly: assessment of Achilles tendon with sonoelastography. Medical ultrasonography. 2016;18(1):30-35.

44. Ozturk M, Sayinbatur B. Real-time ultrasound elastography of the Achilles tendon in patients with cerebral palsy: is there a correlation between strain ratio and biomechanical indicators? Journal of medical ultrasonics (2001). 2017.

45. Porta F, Damjanov N, Galluccio F, lagnocco A, MatucciCerinic M. Ultrasound elastography is a reproducible and feasible tool for the evaluation of the patellar tendon in healthy subjects. International journal of rheumatic diseases. 2014; 17(7):762-766.

46. Ozcan AN, Tan S, Tangal NG, Ciraci S, Kudas S, Bektaser SB, et al. Real-time sonoelastography of the patellar and quadriceps tendons: pattern description in professional athletes and healthy volunteers. Medical ultrasonography. 2016;18(3):299304.

47. Tas S, Yilmaz S, Onur MR, Soylu AR, Altuntas O, Korkusuz F. Patellar tendon mechanical properties change with gender, body mass index and quadriceps femoris muscle strength. Acta orthopaedica et traumatologica turcica. 2017; 51(1):54-59.

48. Tas S, Onur MR, Yilmaz S, Soylu AR, Korkusuz F. Shear Wave Elastography Is a Reliable and Repeatable Method for Measuring the Elastic Modulus of the Rectus Femoris Muscle and Patellar Tendon. Journal of ultrasound in medicine: official journal of the American Institute of Ultrasound in Medicine. 2017;36(3):565-570.

49. Ooi CC, Richards PJ, Maffulli N, Ede D, Schneider ME, Con- nell $D$, et al. A soft patellar tendon on ultrasound elastography is associated with pain and functional deficit in volleyball players. Journal of science and medicine in sport. 2016;19(5):373378.

50. Botanlioglu H, Kaynak G, Kantarci F, Guven MF, Zengin G, Aydingoz $\mathrm{O}$. Length, thickness, and elasticity of the patellar tendon after closed wedge high tibial osteotomy: a shear wave elastographic study. Journal of orthopaedic surgery (Hong Kong). 2016;24(2):194-197.

51. Akkaya S, Akkaya N, Agladioglu K, Gungor HR, Ok N, Ozcakar L. Real-time elastography of patellar tendon in patients with auto-graft bone-tendon-bone anterior cruciate ligament reconstruction. Archives of orthopaedic and trauma surgery. 2016;136(6):837-842.

52. Teber MA, Ogur T, Bozkurt A, Er B, Turan A, Gulbay M, et al. Real-time sonoelastography of the quadriceps tendon in patients undergoing chronic hemodialysis. Journal of ultrasound in medicine: official journal of the American Institute of Ultrasound in Medicine. 2015;34(4):671-677.

53. Baumer TG, Dischler J, Davis L, Labyed Y, Siegal DS, van Holsbeeck M, et al. Effects of age and pathology on shear wave speed of the human rotator cuff. Journal of orthopaedic research: official publication of the Orthopaedic Research Society. 2017

54. Dischler JD, Baumer TG, Finkelstein E, Siegal DS, Bey MJ. Association Between Years of Competition and Shoulder Function in Collegiate Swimmers. Sports health. 2017: 1941738117726771.

55. Lee SU, Joo SY, Kim SK, Lee SH, Park SR, Jeong C. Realtime sonoelastography in the diagnosis of rotator cuff tendinopathy. Journal of shoulder and elbow surgery/American Shoulder and Elbow Surgeons [et al]. 2016;25(5):723729.

56. Krepkin K, Bruno M, Raya JG, Adler RS, Gyftopoulos S. Quantitative assessment of the supraspinatus tendon on MRI using T2/T2* mapping and shear-wave ultrasound elastography: a pilot study. Skeletal radiology. 2017;46(2):191-199.

57. Kocyigit F, Kuyucu E, Kocyigit A, Herek DT, Savkin R, Aslan UB. Investigation of Biomechanical Characteristics of Intact Supraspinatus Tendons in Subacromial Impingement Syndrome: A Cross-sectional Study with Real-time Sonoelastography. American journal of physical medicine \& rehabilitation/Association of Academic Physiatrists. 2016;95(8):588596.

58. Seo JB, Yoo JS, Ryu JW. Sonoelastography findings of biceps tendinitis and tendinosis. Journal of ultrasound. 2014;17(4): 271-277.

59. Tudisco C, Bisicchia S, Stefanini M, Antonicoli M, Masala S, Simonetti $\mathrm{G}$. Tendon quality in small unilateral supraspinatus tendon tears. Real-time sonoelastography correlates with clinical findings. Knee surgery, sports traumatology, arthroscopy: official journal of the ESSKA. 2015;23(2):393-398.

60. Hou SW, Merkle AN, Babb JS, McCabe R, Gyftopoulos S, Adler RS. Shear Wave Ultrasound Elastographic Evaluation of the Rotator Cuff Tendon. Journal of ultrasound in medicine: official journal of the American Institute of Ultrasound in Medicine. 2017;36(1):95-106.

61. Baumer TG, Davis L, Dischler J, Siegal DS, van Holsbeeck M, Moutzouros V, et al. Shear wave elastography of the supraspinatus muscle and tendon: Repeatability and preliminary findings. Journal of biomechanics. 2017;53:201-204.

62. De Zordo T, Lill SR, Fink C, Feuchtner GM, Jaschke W, Bellmann-Weiler R, et al. Real-time sonoelastography of lateral epicondylitis: comparison of findings between patients and healthy volunteers. AJR American journal of roentgenology. 2009;193(1):180-185.

63. Arslan S, Karahan AY, Oncu F, Bakdik S, Durmaz MS. Diagnostic Performance of Superb Microvascular Imaging and 
Other Sonographic Modalities in the Assessment of Lateral Epicondylosis. 2017.

64. Ahn KS, Kang CH, Hong SJ, Jeong WK. Ultrasound elastography of lateral epicondylosis: clinical feasibility of quantitative elastographic measurements. AJR American journal of roentgenology. 2014;202(5):1094-1099.

65. Kocyigit F, Kuyucu E, Kocyigit A, Herek DT, Savkin R, Aslan UB, et al. Association of real-time sonoelastography findings with clinical parameters in lateral epicondylitis. Rheumatology international. 2016;36(1):91-100.

66. Sconfienza LM, Silvestri E, Orlandi D, Fabbro E, Ferrero G Martini $\mathrm{C}$, et al. Real-time sonoelastography of the plantar fascia: comparison between patients with plantar fasciitis and healthy control subjects. Radiology. 2013;267(1):195-200.

67. Wu CH, Chang KV, Mio S, Chen WS, Wang TG. Sonoelastography of the plantar fascia. Radiology. 2011;259(2):502507.

68. Wu CH, Chen WS, Wang TG. Plantar fascia softening in plan- tar fasciitis with normal B-mode sonography. 2015;44 (11): 1603-1607.

69. Tas S, Bek N, Ruhi Onur M, Korkusuz F. Effects of Body Mass Index on Mechanical Properties of the Plantar Fascia and Heel Pad in Asymptomatic Participants. Foot \& ankle international. 2017;38(7):779-784.

70. Kim M, Choi YS, You MW, Kim JS, Young KW. Sonoelastography in the Evaluation of Plantar Fasciitis Treatment: 3-Month Follow-Up After Collagen Injection. Ultrasound quarterly. 2016;32(4):327-332.

71. Klauser AS, Miyamoto $\mathrm{H}$, Tamegger M, Faschingbauer R, Moriggl B, Klima G, et al. Achilles tendon assessed with sonoelastography: histologic agreement. Radiology. 2013; 267(3):837-842.

72. Klauser AS, Pamminger M, Halpern EJ, Abd Ellah MMH, Moriggl B, Taljanovic MS, et al. Extensor tendinopathy of the elbow assessed with sonoelastography: histologic correlation. European radiology. 2017;27(8):3460-3466. 